\title{
Los comerciantes de Guatemala y la economía de Centroamérica en la primera mitad del siglo XVIII
}

\author{
José Manuel Santos Pérez \\ Dpto. de Historia Medieval, Moderna y Comtemporánea \\ Universidad de Salamanca
}

Las actividades diversas de los comerciantes de Guatemala en la primera mitad del siglo XVIII reflejan una realidad de la Centroamérica colonial rica y compleja y nos dan una imagen de este período distinta de la que hasta ahora se ha presentado. No parece ya un período oscuro, previo al gran incremento de la exportación del añil que se produjo en la segunda mitad del siglo, sino un momento especialmente atractivo de la historia económica regional.

El gran incremento en la producción de añil que se registró en Centroamérica en la segunda mitad del siglo XVIII, provocado según algunos autores por el impacto de las incipientes reformas borbónicas y según otros por el aumento de la demanda consecuente a la Revolución Industrial, es el asunto que ha atraído con más fuerza la atención de los historiadores centroamericanistas desde hace años, dejando en la oscuridad casi total el período precedente. Teniendo en cuenta que desde mediados del siglo XVII se constataba la existencia de una importante reducción en el flujo de mercancías que entraban o salían de la región por vía "oficial" a través de Honduras, la primera mitad del XVIII, aun presentando signos de recuperación, sería la sombría antesala del brillante período posterior. Esta interpretación, que se basa casi de forma unitaria en los intercambios externos de la economía colonial centroamericana, tiene su origen en el famoso planteamiento de Murdo Macleod sobre los ciclos económicos centroamericanos, según el cual el fin de un boom en una mercancía de exportación determinaría el comienzo de una situación de crisis económica general que sólo se solucionaría con el siguiente boom exportador. ${ }^{1}$ Así se pasó del cacao en el siglo XVI a la primera etapa del añil a principios del XVII; y de ahí a la etapa de gran crecimiento exportador que surgiría a partir de 1750 .

En nuestra opinión, las décadas finales del siglo XVII y la primera mitad del siglo XVIII deben ser examinadas desde otro enfoque. Sin pretender dejar a un lado la importancia fundamental del comercio exterior para la región

1 Macleod, Murdo: Spanish Central America. A Socioeconomic History, 1520-1720, Los Angeles, 1973. 
centroamericana, debemos tener en cuenta sin embargo que ése no era el único componente de la economía de la región. Obviamente existían otros sectores que completaban la realidad económica de la zona, en los cuales desarrollaron sus actividades algunos de los más prominentes comerciantes de la época. Estos hombres de negocios tenían clara la consigna para resistir y prosperar en el cambiante y vulnerable mundo de la Centroamérica colonial: diversificación de actividades. Esta diversificación les permitió no sólo sobrevivir en los momentos en que el tráfico directo entre Honduras y Cádiz quedó prácticamente paralizado (sobre todo en los años del cambio de siglo), sino incluso amasar importantes fortunas. La élite de comerciantes se involucró, en esta primera mitad del siglo XVIII, en la mayoría de los conductos del comercio que, una vez descartado el tráfico oficial de mercancías por medio de navíos de registro entre Cádiz y Honduras, aún subsistían en la economía regional. Éstos eran, por un lado, los canales para el comercio exterior diferentes al "oficial" mencionado anteriormente: la exportación-importación de productos a través de Veracruz y La Habana, y el sector de comercio externo menos conocido, el contrabando, que a principios del XVIII se realizaba sobre todo con comerciantes ingleses; en segundo lugar, el comercio intercolonial, en el caso centroamericano principalmente con México, La Habana y Perú; y por último, el comercio interno, entendido éste como el flujo de mercancías entre las distintas zonas que componían el llamado "Reino de Guatemala" (todo el área centroamericana sin Panamá más el actual estado mexicano de Chiapas). Otras actividades, como agricultura para el consumo local y para la exportación, ganadería, minería y transportes, también jugaban un papel en la trama. Sólo una visión global, que contemple y dé la importancia que merecen esos sectores diversos, puede llevarnos a una mejor comprensión de la realidad colonial centroamericana en esos momentos "oscuros". Intentaremos en el presente ensayo profundizar en nuestro conocimiento de esta compleja trama, siguiendo las actividades de algunos de los comerciantes guatemaltecos más activos durante la primera mitad del siglo. Entre ellos había tanto recién llegados como hijos de peninsulares nacidos en Guatemala o descendientes de rancias familias criollas. Casi todos utilizaron las redes familiares y el entramado burocrático colonial para conseguir mayores ventajas económicas y unas mejores posiciones sociales. Todos aprendieron que un aprovechamiento inteligente de esos resortes, unido a la imprescindible diversificación de actividades, les daría la seguridad económica y la reproducción de su status en un lugar étnicamente complejo y considerado marginal en el sistema colonial hispano en América. 
Aunque nuestra intención aquí sea la de relativizar la importancia del sector externo en el conjunto de la economía regional, no cabe duda de que seguía siendo un elemento fundamental y por él comenzaremos nuestro análisis. El comercio exterior de Centroamérica en estos primeros años del siglo XVIII se desarrollaba con el gran handicap de la casi nula relación directa entre Honduras y Cádiz. (Ver gráficos I y II).

A falta de navíos de registro oficiales que colocaran los productos en España, los comerciantes guatemaltecos tuvieron que utilizar tres vías diferentes para alcanzar el mercado europeo: la salida de productos por Veracruz, la conexión con la Habana y el contrabando. Sabemos que una gran cantidad de mercancías salieron en dirección a Veracruz por la ruta terrestre que unía la parte central de Guatemala con Oaxaca para dirigirse después al Atlántico. Hay menos evidencias sobre la conexión con Cuba y el contrabando, pero su importancia era fundamental. Miguel Eustaquio de Uría, uno de los más importantes comerciantes de las primeras décadas del XVIII, utilizó frecuentemente estas vías alternativas de exportación de productos en la fachada atlántica. Uría desplegó su actividad entre los años 1720-1740. Nacido en Santiago de Guatemala en 1680, tuvo indudablemente a su padre, Juan Ignacio de Uría, como guía y consejero. Juan Ignacio, natural de Sanlúcar, había emigrado a Guatemala pocos años antes del nacimiento de su hijo, y había establecido ya una importante red comercial.

Los datos que tenemos de la actividad de Miguel Eustaquio de Uría, al primer golpe de vista, resultan paradójicos. Según los registros de los barcos que hacían la ruta entre Cádiz y Honduras, Uría sólo importó 74 quintales de hierro y 10 cajones de textiles por esta vía "oficial" entre 1700 y 1740. Sus exportaciones en este período se limitaron a 200 arrobas de chocolate, 32.000 vainillas y algo de carmín. ${ }^{2}$ Son cifras escasas cuando las comparamos con otros datos de la actividad comercial de Uría, cuya trayectoria fue claramente ascendente durante este período. Si entre los años 1717-1726 logró colocar mercancías por valor de 53.000 pesos a lo largo y ancho de Centroamérica, más tarde, en un solo año, 1738, logró vender mercancías por un valor de casi 28.000 pesos. ${ }^{3}$ Aunque en las escrituras figura el término

2 Archivo General de Indias (AGI). Contratación, 2598-2606. Registros que vinieron de Honduras, 1700-1769.

3 Archivo General de Centroamérica (AGCA). A1-20, leg. 866, exp. 9359, fols. 34v., 38v., 39, 45, 51v., 53, 55, 56, 59v., 60, 61, 65, 67v., 69v., 71v., 74v., 75, 90v., 93v., 102v., 133v., 149v., 161, 164, 173, 245v., 265, 312, 325, 325v., 326v., 349v., 361, 366, 381, 438, 457v. Protocolos de Antonio González, diversas escrituras de obligación de pagos por compra de géneros a favor de Miguel Eustaquio de Uría, año 1738. 


\section{GRÁFICO I}

BARCOS QUE SALIERON DE HONDURAS HACIA ESPAÑA, 1535-1829

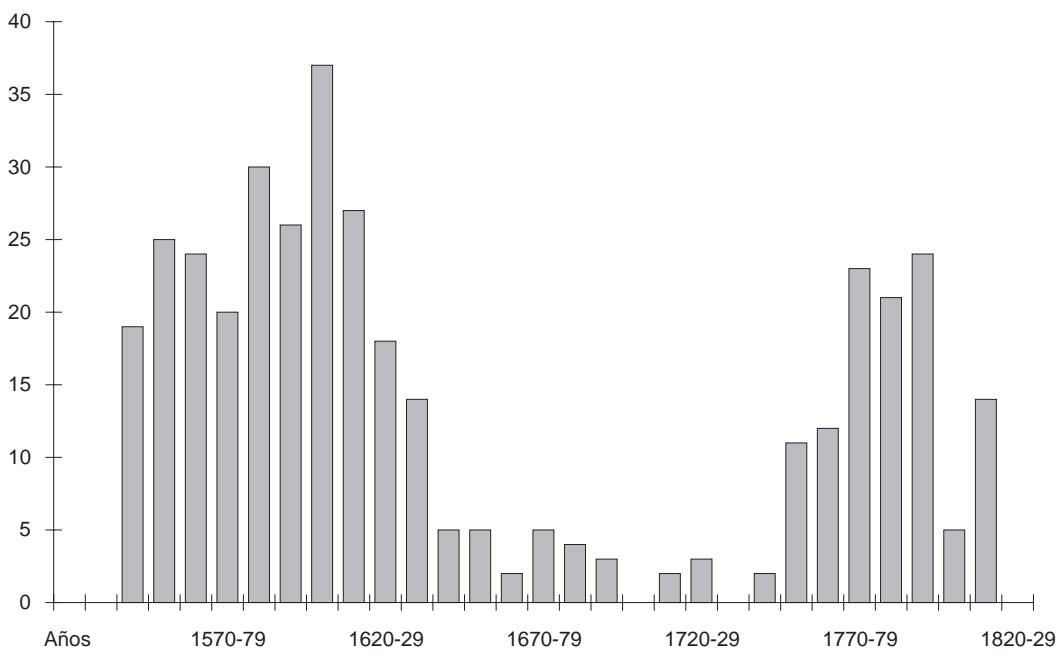

\section{GRÁFICO II}

BARCOS QUE LLEGARON A HONDURAS DESDE ESPAÑA, 1535-1829

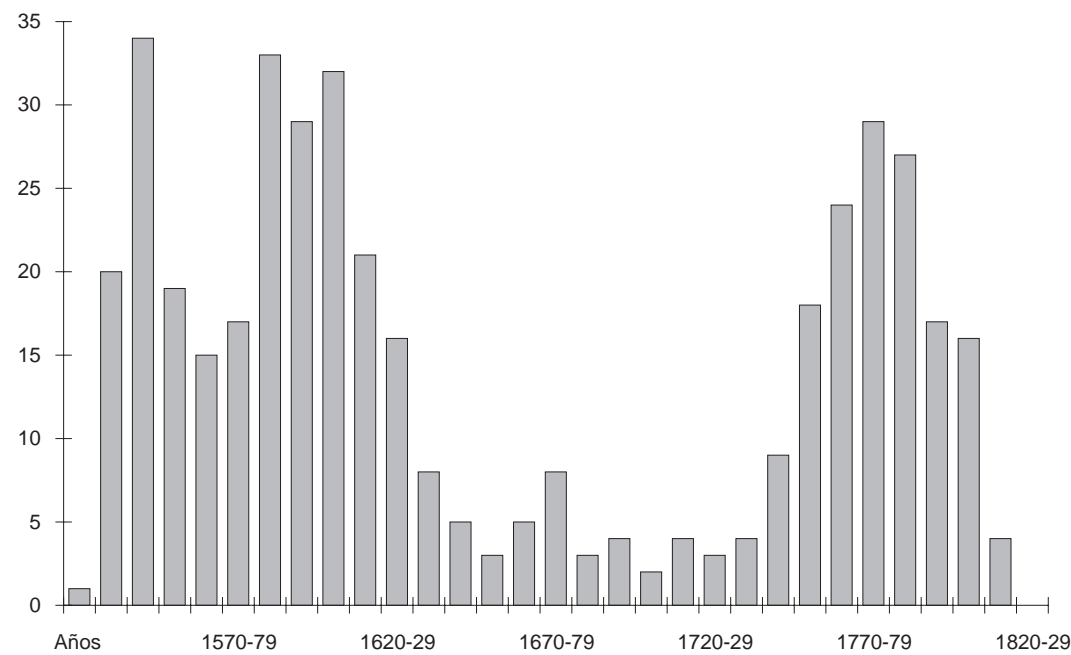

Fuente: Palma, Gustavo: "Agriculture, Commerce et Société au Royaume du Guatemala, 17701821”. Tesis Doctoral inédita, Institute des Hautes Études en Sciences Sociales, Paris, 1985. Capítulo IV. 
general de "géneros de Castilla, China y de la tierra" para describir los productos vendidos, no cabe duda de que una buena parte eran importaciones de origen europeo. Otra prueba de esta afirmación es el hecho de que en ese mismo año 1738 Uría firmó obligaciones para comerciantes en Cádiz por un valor de 21.125 pesos, incluidos los intereses del $25 \%$. Dado que en toda la década 1730-1739 sólo llegaron tres barcos a las costas de Honduras procedentes de Cádiz, ¿cuál era la vía de entrada de estos productos comprados en la Península?, ¿había otras formas de aprovisionamiento de mercancías del exterior? Sin duda, Uría estaba usando en estos momentos las otras vías de salida y entrada de productos atlánticos en Centroamérica: Veracruz, la conexión directa con la Habana y el contrabando.

La ruta hacia Nueva España, según todos los datos que poseemos, era la más importante vía de exportación-importación durante la primera mitad del siglo XVIII. Veracruz fue durante muchos años el principal puerto de salida del añil guatemalteco exportado a España, algo que levantaba amargas quejas entre los diputados del comercio guatemaltecos, que intentaban por todos los medios que la producción saliera por los puertos de Honduras hacia La Habana. Sin embargo, la escasez de barcos que llegaban a los puertos atlánticos del istmo obligaba a los exportadores a utilizar la difícil ruta mexicana. Después de la feria del añil que se celebraba cada año en Apastepeque entre el mes de febrero y finales de marzo, los trenes de mulas partían de Santiago llevando añil a la ciudad de Oaxaca. El viaje duraba normalmente cuatro meses, pero con frecuencia algunos de los cargamentos no llegaban hasta finales de julio o principios de agosto. Oaxaca era el límite hasta el que podían llegar los arrieros guatemaltecos y allí las cargas debían ser transferidas a las reatas mexicanas, cuyos conductores ponían un alto precio por el transporte. ${ }^{4}$ Desde allí se continuaba viaje a Veracruz, donde el añil era intercambiado por los productos que llegaban de la Península, sobre todo textiles, aguardientes y artículos de ferretería, que eran llevados a los almacenes de Santiago o se utilizaban en la feria de Apastepeque para utilizarlos en la compra de nuevos cargamentos de añil. Los intermediarios mexicanos, que finalmente se encargaban de embarcar la mercancía, se llevaban la mayor parte del beneficio. ${ }^{5}$ Prueba de estos inter-

4 Meneray, Wilbur E.: "The Kingdom of Guatemala during the Reign of Charles III, 17591788". Tesis doctoral inédita, University of North Carolina at Chapel Hill, 1975, pág. 141.

5 Acuña Ortega, V. H.: "Le Commerce Exterieur du Royaume du Guatemala au XVIIIème Siècle, 1700-1821: Une étude Structurelle". Tesis doctoral inédita, París, École des Hautes Études en Sciences Sociales, 1978, pág. 242. 
cambios comerciales es una escritura que firma Miguel Eustaquio de Uría con dos arrieros que hacen la ruta desde y hacia Nueva España, por la que éstos últimos se comprometen a pagar a Uría cierta cantidad de pesos por haberse dañado una parte de la carga. Las mercancías transportadas eran vidrio, bretañas y marquetas de cera, todos productos importados desde Cádiz. ${ }^{6}$ El impago de esta cantidad determinó que Uría se quedara con la recua de mulas del arriero. ${ }^{7}$ No sólo Uría usaba esta vía de salida de productos. Otro importante comerciante de la época, Francisco Marcelino Falla, tenía sólidas relaciones a través de Oaxaca. Por esa vía sacó en los primeros años del siglo XVIII grandes cantidades de añil, algodón y textiles que entregaba a Pedro Barrios, su agente en la ciudad. ${ }^{8}$

El comercio con Nueva España no se limitaba al paso de añil para ser reexportado a la Península. Existía un comercio directo con el virreinato, que consumía una parte del añil (según Acuña Ortega unas 200.000 libras al año) y que enviaba productos a Guatemala, como textiles, cerámica o marroquinería. ${ }^{9}$ Datos de finales del siglo XVIII nos informan de que la parte de los productos exportados que se quedaba en Nueva España era escasa, pues hasta un $90 \%$ de lo que se transportaba por esta vía iba dirigido a Veracruz para su reexportación. Parece probable, sin embargo, que en la primera mitad del siglo la proporción del añil exportado que iba destinada a Nueva España fuera mayor. Macleod argumentó en su clásica obra sobre Centroamérica colonial que una de las causas de la crisis de la segunda mitad del XVII en el sector exportador fue la dificultad para encontrar mercados alternativos, una vez que la ruta hacia Cádiz por los puertos de

6 AGCA. A1-20, leg. 860, exp. 9353, fol. 75v. Protocolos de Antonio González, 1732.

7 AGCA. A1-15, leg. 2456, exp. 19073. Protocolos de Antonio González, 1738.

8 AGCA. A1-20, leg. 1281, fol. 15v. Protocolos de Mateo Ruiz Hurtado, 21 de marzo de 1725, obligación de Thomas Brau, dueño de recua, a favor de don Francisco Marcelino Falla para entregar 24 tercios de tinta y 60 pesos en Oaxaca a don Pedro Antonio de Barrios. AGCA. A1-20, leg. 1272, fol. 11. Protocolos de Mateo Ruiz Hurtado, 4 de marzo de 1719, obligación de Juan de Alvarez, arriero, en favor de don Francisco Marcelino Falla, para llevar 22 tercios de hilo de algodón a Oaxaca. AGCA. A1-20, leg. 1272, fol. 12. Protocolos de Mateo Ruiz Hurtado, 10 de marzo de 1719, obligación de Juan Velasquez a favor de Fco. Marcelino Falla, para llevar 6 tercios de tinta flor, 6 tercios de algodón, 12 tercios a la ciudad de Oaxaca. AGCA. A1-20, leg. 1272, fol. 61. Protocolos de Mateo Ruiz Hurtado, 5 de dic. de 1719, obligación de Simón Rodrigo Mendes, dueño de Requa, a favor de don Francisco Marcelino Falla, para entregar 33 fardos arpillados en la ciudad de Oaxaca. AGCA. A1-20, leg. 1273, fol. 60. Protocolos de Mateo Ruiz Hurtado, 5 de marzo de 1718, obligación de don Pedro de Loaiza, dueño de recua a favor de don Franco. Marcelino Falla, para entregar 94 tercios de tinta añil, a Pedro Barrios en la ciudad de Oaxaca. AGCA. A1-20, leg. 1276, fol. 1. Protocolos de Mateo Ruiz Hurtado, 4 de enero de 1721, obligación de Domingo González, dueño de recua, a favor de don Francisco Marcelino Falla para entregar 38 fardos de naguas de telar a Pedro Barrios en la ciudad de Oaxaca.

9 Acuña Ortega: "Le commerce extérieur ...” , págs. 242-246. 
Honduras había quedado prácticamente cortada. Sin embargo, el mercado mexicano sí absorbió parte de la producción centroamericana, sobre todo de añil. Macleod descarta la posibilidad de que Nueva España se convirtiera en mercado alternativo por el hecho de que se producía añil también allí. Pero no cuenta con un factor importante: la excelente calidad del añil guatemalteco (en su variante flor), que era considerado en la época como el mejor del mundo. A pesar de las dificultades de la ruta a través de Oaxaca, que seguramente tendría una incidencia en el precio final, el añil guatemalteco pudo conservar su competitividad en el mercado de Nueva España. ${ }^{10}$ Hay evidencias de que los comerciantes guatemaltecos lograron colocar una gran cantidad de tinte en ciudades textiles como Puebla. Podemos comprobarlo en la declaración de capital de Juan José González Batres, otro de los comerciantes radicados en Guatemala de esta primera mitad de siglo. Juan José González Batres desarrolló sus negocios entre los años 20 a 50, participando así de los primeros momentos del boom del añil. La evolución de su fortuna indica a las claras su éxito en los negocios. En la declaración de bienes que efectuó con motivo de su primer matrimonio en 1721 su capital ascendía a 68.701 pesos. En su segundo matrimonio, en 1741, volvió a hacer recuento de sus posesiones y la cifra alcanzaba ya los 169.804 pesos, un crecimiento del $247 \%$ en 20 años. Una parte sustancial, sin embargo, figuraba bajo el epígrafe "deudas". El total por cobrar ascendía a 113.086 pesos, un 66\% del patrimonio total. Un análisis geográfico de la distribución de estas deudas nos da cuenta de la importancia que alcanzaba la conexión mexicana, y en concreto Puebla, en las actividades del comerciante (Ver Tabla 1 y Gráfico III). Como era lo normal en la mayor parte de los comerciantes prestamistas, el grueso de las "habilitaciones" u operaciones crediticias de González Batres iba a las provincias de Tegucigalpa y de San Salvador. El volumen de deudas alcanzado por Veracruz nos indica que los productos exportados por Juan José eran enviados por la ruta mexicana hacia los navíos que zarpaban desde esa ciudad. Eso muestran también otras fuentes consultadas como los documentos de los navíos de registro que partían de las costas de Honduras, en los que Batres embarcó cantidades escasas. ${ }^{11}$ Como se puede ver, las deudas de Puebla (15.253 pesos) dejan claro que una parte importante del añil expor-

10 Macleod: Spanish Central America..., pág. 389.

11 AGI. Contratación, 2598-2606. Registros que vinieron de Honduras, 1700-1769. En Cádiz mantenía estrechas relaciones con la compañía comercial de Pardo, Vasquez y Freyre, a cuyo nombre consignaba la mayor parte de los envíos (unas 13.568 libras de añil desde los puertos de Honduras). 
tado por Batres se dirigía a los obrajes de esa ciudad. ${ }^{12}$ Un tal Pedro Moreno representaba a Batres en Veracruz, ${ }^{13}$ y Andrés Garai, en Puebla, recibía los zurrones de añil y le remitía a cambio "ropa de la tierra". En Cádiz, al final del largo periplo, le quedaban por cobrar más de 8.000 pesos. Puebla era, por lo tanto, uno de los principales centros de la actividad comercial de Batres. En proporción, sólo Tegucigalpa y Salvador superaban a la ciudad mexicana en las cantidades adeudadas.

El añil no era el único producto que se transportaba a través de la ruta mexicana. Como veremos más adelante al tratar del mercado interno, buena parte del cacao, cochinilla y textiles de algodón conseguidos de forma compulsiva por los alcaldes mayores en las comunidades indígenas, llegaban a Oaxaca bien para su reexportación o para su consumo en Nueva España.

La tercera vía exportadora que hemos enumerado era el contrabando. Macleod da a la actividad contrabandística una importancia especial. Según el historiador escocés el comercio ilícito adquirió enormes proporciones en la crisis de la segunda mitad del siglo XVII y habría sido el principal causante de la recuperación económica que según él se produjo en los primeros años del siglo XVIII. ${ }^{14}$ Otros autores, como Víctor H. Acuña, se han mostrado contrarios a esa idea proclamando la poca importancia que tendría esta actividad en la estructura global de la economía centroamericana. ${ }^{15}$ Lo que parece incontestable es que el fenómeno no se circunscribió a los períodos de depresión del comercio en el Atlántico sino que fue un elemento recurrente de la historia colonial de Centroamérica. Personas con altos cargos burocráticos participaron activamente en la actividad contrabandística, consiguiendo así un aporte adicional a sus ingresos ordinarios. ${ }^{16}$ Los comerciantes de la capital, en ningún modo ajenos al contrabando, nombraban agentes en lugares costeros como Gracias a Dios, donde establecían sus líneas comerciales con los ingleses. ${ }^{17} \mathrm{Al}$ menos en el caso de

12 Sobre la industria de textil de Puebla véase Thomson, Guy: "The Cotton Textile Industry in Puebla during the Eighteenth and Early Nineteenth Centuries" en Jacobsen, Nils y Puhle, Hans-Jürghen (eds.): The Economies of Mexico and Peru During the Late Colonial Period, 1760-1810, Berlín, 1986. Entre los bienes del tejedor José García de Aragón figuraban 900 libras de añil, pág. 190.

13 AGCA. A1-20, leg. 1075, fol. 296. Protocolos de Manuel Monzón, poder general para cobranzas que otorga Juan José González Batres a favor de Pedro Moreno, vecino de Veracruz (1727).

14 Macleod: Spanish Central America..., págs. 374-389.

15 Acuña Ortega: "Le Commerce extérieur...", págs. 256-257. pág. 103 .

16 Wortman, Miles: Gobierno y sociedad en Centroamérica, 1680-1840, San José, 1991,

17 Szaszdi de Nagy, Adam: "El comercio ilícito en la provincia de Honduras," Revista de Indias, vol. 17, n. ${ }^{\circ}$ 68, Abril-junio, 1957, págs. 271-283. 


\section{TABLA 1}

CAPITAL ADEUDADO A JUAN JOSÉ GONZÁLEZ BATRES

(No hay distinción entre deudas cobrables y no cobrables)

valor total valor relativo
(en pesos)

\begin{tabular}{|c|c|c|}
\hline 1. Tegucigalpa: & 17.857 p. 5 r. & $(15 \% 8 \%)$ \\
\hline 2. San Vicente: & $10.912,1 / 2$ & $(9 ’ 6 \%)$ \\
\hline 3. Santa Anna: & $138,21 / 2$ & \\
\hline 4. San Miguel: & $12.372,4 \frac{1}{2}$ & $(10 ’ 9 \%)$ \\
\hline $\begin{array}{l}\text { 5. San salvador: } \\
2+3+4+5\end{array}$ & $2.250,4$ & $\begin{array}{l}(1 ' 98 \%) \\
\left(222^{\prime} 7 \%\right)\end{array}$ \\
\hline 6. Segovia: & $3.417,6$ & \\
\hline 7. Oaxaca: & $96,61 / 2$ & \\
\hline 8. Veracruz: & $10.888,13 / 4$ & $\left(9^{\prime} 6 \%\right)$ \\
\hline 9. Comaiagua: & $177,71 \frac{1}{2}$ & \\
\hline 10. Sula: & $694,1 / 2$ & \\
\hline 11. Olancho: & $2.225,1$ & \\
\hline 12. Sinacantan: & $212,51 / 2$ & \\
\hline 13. Granada: & $411,41 / 2$ & \\
\hline 14. V. del Dorado: & $167,13 / 4$ & \\
\hline 15. Matagalpa: & 232,4 & \\
\hline 16. Gracias a Dios: & $6.596,33 / 4$ & $(5,83 \%)$ \\
\hline 17. Puebla: & $15.253,5$ & $\left(13^{\prime} 48 \%\right)$ \\
\hline 18. Chuluteca: & $5.573,11 \frac{1}{2}$ & $(4 ’ 9 \%)$ \\
\hline 19. Leon: & $2.628,2$ & \\
\hline 20. Nacaome: & $2.736,6$ & \\
\hline 21. Santiago de Guatemala: & $6.248,21 / 2$ & $(5,5 \%)$ \\
\hline 22. Cádiz: & $8.422,61 / 2$ & $(7 ’ 4 \%)$ \\
\hline 23. Chiquimula: & $313,21 / 2$ & \\
\hline 24. Petapa: & 194 & \\
\hline Otros (de orígen desconocido): & $3.064,31 \frac{1}{2}$ & \\
\hline Total: & 113.086 peso & eales \\
\hline
\end{tabular}

Fuente: AGCA. A1-20, leg. 1140, exp. 9633, fol. 82v. y ss. Protocolos de Hipólito Ordóñez, declaración de capital de Juan José González Batres, 1741. 


\section{GRÁFICO III}

ORIGEN DEL CAPITAL ADEUDADO A JUAN JOSÉ GONZÁLEZ BATRES

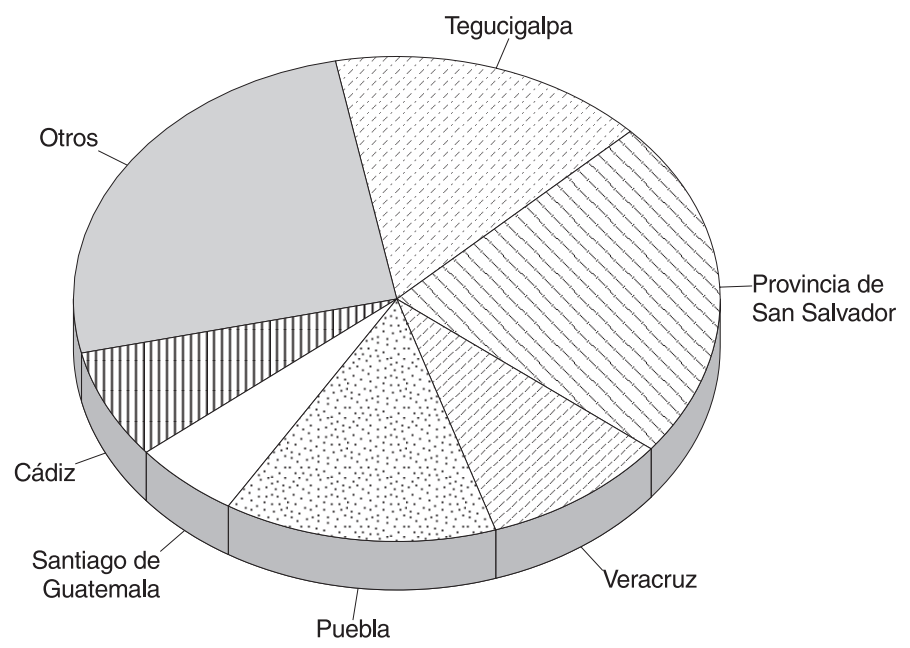

Fuente: Ver tabla 1.

Uría, el comercio con los británicos representaba una parte importante en sus negocios. En 1723, el comerciante fue acusado de proteger al gobernador de Honduras, Enrique Logman, en sus tratos ilícitos con los ingleses, y de haber participado él mismo en el contrabando. Un testigo afirmó que entre los años 1710 a 1714, Miguel Eustaquio comerció por valor de 17.000 pesos con los ingleses que llegaban a las costas caribeñas. Otro testigo fue aún más preciso. Declaró que Miguel Uría vendió 4.000 vainillas al capitán de una balandra inglesa, un tal Pedro Tirpi, y al mercader judío Francisco Ferro. Los ingleses intercambiaron las vainillas, valoradas en 100 pesos, por anascotes, una tela de fabricación holandesa, a razón de 15 pesos la pieza. ${ }^{18}$

El comercio intercolonial fue también una importante salida para las mercancías del Reino de Guatemala, por mucho que Macleod insista en la "escasez de mercados" como uno de los factores causantes de la crisis

18 AGCA. A3-6, leg. 2751, exp. 39602. Año 1723. 
económica centroamericana de la segunda mitad del XVII. Aparte de las ya examinadas con Nueva España, existían importantes relaciones comerciales con La Habana y Perú, a pesar de los obstáculos legales existentes para este comercio. A través de innumerables peticiones, los comerciantes de Guatemala trataron por todos los medios de hacer comprender a la Corona que era necesario sacar la producción por los puertos de Honduras haciéndola llegar a La Habana, donde podría ser embarcada en el convoy que se dirigiera a la Península. ${ }^{19}$ A lo largo de los siglos XVI y XVII, hubo un comercio esporádico entre las dos regiones, si bien en 1676 se decretó la prohibición de las comunicaciones comerciales entre Guatemala y La Habana. Esta disposición se mantuvo hasta 1760, cuando otra Real Cédula volvió a permitir los contactos. A pesar de estas medidas legales, el tráfico comercial entre las dos zonas continuó produciéndose durante todo este período. Los puertos centroamericanos de los que salían las mercancías eran Omoa y Trujillo. Las mercancías que se intercambiaban eran por el lado guatemalteco añil, madera, plata y zarzaparrilla, y por el lado cubano azúcar, tabaco, café, aguardiente y cera, entre otros. ${ }^{20}$ La navegación se realizaba en barcos pequeños tipo balandra que pudieran escapar más fácilmente al ataque de los abundantes corsarios que en estos momentos se movían por el Caribe. ${ }^{21}$ Indudablemente, Uría tenía en La Habana otra de sus fuentes de aprovisionamiento y de salida de sus exportaciones en esta mitad del siglo XVIII. El comerciante, ajeno a las disposiciones legales contrarias al comercio con la isla, poseía un barco que realizaba la ruta entre Honduras y Cuba y en 1724 nombró a un tal Francisco Antonio Basabe como agente en La Habana para que llevara sus negocios. ${ }^{22}$

19 AGI. Guatemala, 241. Los comerciantes guatemaltecos a través de la diputación de comercio llegaron a gastar 16.800 pesos en la construcción de un camino a Omoa, lo que había mejorado sensiblemente, en su opinión, las comunicaciones con ese puerto.

20 Palma, Gustavo: “Agriculture, Commerce et Société au Royaume du Guatemala, 17701821", Tesis Doctoral inédita, París, École des Hautes Études en Sciences Sociales, 1985. Para este trabajo estamos utilizando una versión traducida en soporte magnético, que el propio doctor Palma nos cedió gentilmente en Guatemala. Al no tener numeración en las páginas, citaremos el capítulo en que se encuentra el párrafo citado, en este caso el IV.

21 Wortman: Gobierno y sociedad..., pág. 104.

22 AGCA. A1-20, leg. 1279, fol. 114. Protocolos de Mateo Ruiz Hurtado, 10 de julio de 1724, poder que otorga don Miguel de Uría a don Antonio Varela, residente en Santiago, y a don Francisco Antonio Basabe, vecino de San Cristóbal de la Habana, "...digo que yo tengo por mia propia una valandra nombrada Nra. Sra. de el Pilar y San Antonio De Padua que hube y compre en nombre público. ... otorgo que doi mi poder ... en primer lugar a don Antonio Varela .... a cada uno en su lugar para que llegada que sea dicha valandra a el prosedan a entender en el desembarque o descarga de los frutos y efectos que de mi quenta y riesgo lleba asegurandolos a su satisfacción". 
El contacto con Perú pronto surgió como la ruta externa más importante después de México y el contrabando. Durante años hubo una agria disputa entre la sociedad centroamericana y la Corona sobre la conveniencia de legalizar la relación comercial entre las dos regiones. Los problemas de abastecimiento, argumentaban los vecinos de Santiago, habían llevado al Reino de Guatemala a una situación límite, pues carecían de bienes básicos como vino y aceite, que normalmente llegaban a través de los navíos de registro y que no se podían producir en la región. La solución, decían, era importar estos bienes de Perú. La Corona finalmente accedió y en 1718 permitió una relación comercial limitada. Los peruanos podían enviar a Guatemala 30.000 botijas de vino al año y 200.000 ducados de plata acuñada, lo que podía ser intercambiado solamente por productos de la tierra. Las mercancías que Guatemala podía dar a cambio eran sobre todo brea, madera y otros materiales para construcción naval, palo brasil y, por supuesto, añil. Según Wortman, en 1647, unos años antes del período tratado aquí, Nueva Segovia llegó a exportar un millón de libras de brea hacia Perú. ${ }^{23}$ No cabe duda de que el comercio con el Pacífico había sido y seguiría siendo uno de los más importantes sectores de la economía colonial centroamericana. La ruta siempre dejaba un saldo favorable a Guatemala, pagado con plata. El metal peruano, que en siglos anteriores había sido el más utilizado en los intercambios comerciales, pasó a ser usado únicamente en los intercambios interiores, tras la creación de la casa de la moneda en Santiago de Guatemala en 1731. Se calcula que el promedio importado estuvo lejos de los 200.000 ducados permitidos en la Real Cédula, situándose en torno a los 80.000 pesos año. Acuña Ortega ha destacado el carácter complementario que tenía la relación comercial con Perú, al suministrar productos dificilmente disponibles por via atlántica. ${ }^{24}$ Uría aparece directamente involucrado en el comercio con Perú desde 1733. En esa fecha aparece otorgando un poder a un capitán de navío para que administre el barco "Santo Cristo de los Milagros y San Francisco Javier", que estando en el puerto de El Realejo se disponía a efectuar viaje a Perú. Las escalas iban a ser, en el viaje de vuelta, Guayaquil y Paita. El navío pasó a ser propiedad de Uría al morir su anterior dueño, Javier Aguirre, de quien el comerciante guatemalteco se había constituido en fiador. La deuda contraída con Uría y otros acreedo-

23 Wortman: Gobierno y sociedad..., pág. 104.

24 Acuña Ortega: "Le Commerce extérieur ...”, pág. 247. 
res en el momento de la muerte de Aguirre ascendía a 56.140 pesos. Uría se comprometió a cumplir con las obligaciones de su deudor vendiendo la carga del barco (consistente en 1.500 quintales de palo brasil y 331 cajones de brea) o el mismo barco, en caso de que el heredero de Aguirre no aceptara sus deudas. ${ }^{25}$

$\mathrm{Si}$ en todos estos intercambios con regiones del exterior que hemos presentado uno de los principales productos que se utilizaba era el añil, ello nos lleva a preguntarnos por la situación de la producción de la planta tintórea durante estos años, previos al denominado "boom" del añil de mediados del siglo XVIII. La información sobre producción de añil en estos primeros años del siglo es muy escasa. Casi todas las monografías dedicadas al cultivo y comercialización de la planta tintórea dan cifras de producción y exportación a partir de los años 60 ó 70 del siglo XVIII. ${ }^{26}$ Gustavo Palma, en una publicación reciente, habla de una cifra de 450.000 libras exportadas en el total de la década $1710-1719 .{ }^{27} \mathrm{Si}$ bien esos son años de continuos desastres naturales, con epidemias, plagas de langosta $\mathrm{y}$ el fuerte terremoto de 1717 , la cifra nos parece demasiado escasa. ${ }^{28}$ En un informe del presidente de la audiencia de Guatemala, Pedro de Ribera, del año 1734, aparecen cifras, para fechas ligeramente posteriores, muy por encima de las indicadas por Palma. El capitán general informaba de la existencia de "305 haciendas, con 643 obrages, para los quales se nezessitan nueve mil y dos operarios ...”. En cuanto a la producción: “... resultó que aunque por abundar el añil como genero de cosecha en unos años mas que en otros no se puede regular a punto fixo la cantidad que cada año se beneficia no obstante prorrateandose los años buenos y malos se cogeran un año con otro veinte mil arrovas que hacen quinientas mil libras, cuio monto al precio que esta regulado de quatro reales libra es el de ducien-

25 AGCA. A1-20, leg. 1137, exp. 9230. Protocolos de Hipólito Ordóñez, 18 de marzo de 1734.

26 Smith, Robert S.: "La producción y el comercio del añil en el reino de Guatemala", traducido en Luján Muñoz, Jorge (ed.): Economía de Guatemala, 1750-1940, Antología de lecturas y materiales, Guatemala, 1980; Rubio Sánchez: "El añil o xiquilite", Anales de la Sociedad de Geografía e Historia, año XXVI, tomo XXVI, septiembre de 1952. Acuña Ortega da unas cifras de 435.962 libras exportadas en 1716 y 344.111 en 1744, "Le Commerce extérieur...", Apéndice II.

27 Palma, Gustavo: "Economía y sociedad en Centroamérica", en Pinto Soria, Julio (ed.): El régimen colonial. Tomo II de la Historia General de Centroamérica, Madrid, 1993, pág. 258.

28 Wortman hace un recuento de los desastres de los primeros 30 años del siglo XVIII: “... una epidemia general de 1703 a 1715 que mató a "muchos de los naturales"; langostas en 1706 y hambruna adicional; viruela en 1708-1709, ... Luego, en 1717, un gran teremoto sacudió Centroamérica ... Durante los siguientes veinte años, las invasiones de langostas (en 1723-1724, 1732), la viruela (en 1725 y 1733), el sarampión (en 1728) y la sequía (en 1734, 1736 y 1739) azotaron a toda Centroamérica...”, Wortman: Gobierno y sociedad..., pág. 115. 
tos y cinquenta mil ...". ${ }^{29}$ Estas cifras, aunque probablemente exageradas, nos indican que la industria del añil había seguido manteniendo un ritmo de producción considerablemente alto durante un período de escasos o inexistentes contactos directos con Cádiz. Podemos considerar esto como una prueba más de la existencia de rutas alternativas al comercio externo centroamericano en los momentos de mayores dificultades para el tráfico a través de Honduras. Como ya hemos apuntado, Murdo Macleod insiste en la escasez o inexistencia de esos mercados y rutas alternativas a la del comercio atlántico. Sin embargo, en su clásica monografía da una prueba más de la existencia de otras salidas para los productos centroamericanos: un testimonio del año 1700, citado por el gran historiador, muestra que entre 600.000 y 1.000 .000 de libras de añil salían cada año por Veracruz en ese momento. ${ }^{30}$ Para Macleod, esto sería una prueba de que la crisis del XVII se estaba remontando, pero lo que esas cifras demuestran es la enorme capacidad que tenía la ruta terrestre mexicana para la salida de los productos de exportación del Reino de Guatemala y de la gran producción de añil que existía en estos momentos en la región. Tengamos en cuenta que las mayores cantidades que llegaron a exportarse desde Centroamérica en el momento álgido del "boom" del añil (década de los 70) se situaron en torno a 1.400.000 libras, en un momento de gran afluencia de navíos a los puertos del Atlántico. Es evidente que necesitamos estudios más pormenorizados sobre la industria del añil en estos primeros años del siglo XVIII, pero con los escasos elementos de que disponemos parece claro que la industria tenía una importante vitalidad ya en estos momentos. El escaso número de barcos llegados a Honduras enmascara una realidad más compleja y una economía exportadora mucho más diversificada de lo que hasta ahora se ha creído.

¿Qué ocurrió mientras tanto con el mercado interno? ¿Hacia dónde se dirigían los productos llegados del exterior que estos comerciantes adquirían, después de sortear tantas dificultades? El problema del mercado interno nos hace preguntarnos por la naturaleza de la demanda existente dentro del territorio centroamericano. Para poder realizar alguna estimación debemos indagar en primer lugar sobre los datos demográficos del período, finales del siglo XVII y primeras décadas del XVIII. Aunque la información de que disponemos es escasa, todo indica que la recuperación

29 AGI. Guatemala, 241. "Expediente en el que se toma la resolución de levantar la prohibición de la lavor de la tinta añil en aquellas provincias”, 1734.

30 Macleod: Spanish Central America..., pág. 187. 
de la población indígena tras el impacto de la conquista fue muy diferente según las zonas. Si en regiones como Chiapas no hubo un incremento demográfico hasta finales del siglo XVIII, en el Occidente de lo que es hoy la República de Guatemala, donde se concentraba la mayor parte de la población antes y después de la conquista, se aprecia que el siglo XVII es un período de clara recuperación. ${ }^{31}$ Otros sectores de población, como los mestizos y los blancos, crecieron también durante este siglo. También hay ciertos signos de recuperación de la población urbana. Según todos los testimonios, Santiago de Guatemala vivió uno de sus períodos de apogeo durante la parte central del siglo XVII. Se efectuaron numerosas construcciones, entre ellas la catedral, cuya culminación hubiera sido muy difícil en un período de profunda depresión económica. Los datos de población indican que la ciudad pasó de 17.500 habitantes en 1650-1659 a 26.750 en 1680-1689. ${ }^{32}$ Wortman indica, sin embargo, que el período 1700-1720 fue uno de continuas catástrofes naturales que incidieron negativamente en el crecimiento de población. ${ }^{33}$ Es posible que lo que se produjera fuera una ralentización del crecimiento ocurrido en las últimas décadas del XVII. A pesar de ello, los niveles de demanda, sobre todo urbana, debieron mantenerse altos en este momento. Por otra parte, la actividad añilera en San Salvador, que como hemos visto mantenía seguramente unos importantes niveles de producción en estos momentos, generaba una demanda que había que cubrir. Tanto más cuanto que una importante proporción de las "habilitaciones" o créditos de los comerciantes exportadores, poseedores de capital, estaban compuestas por productos de la tierra, sobre todo textiles.

El movimiento de mercancías dirigido a satisfacer esa demanda tenía mucho que ver con las prácticas que llevaban a cabo los alcaldes mayores, genéricamente denominadas repartimiento, que incluían distintos tipos de relaciones económicas compulsivas. La principal era el adelanto del dinero del tributo de los indígenas que después se cobraba en productos (sobre todo productos agrícolas, tanto para el consumo local como para la exportación) a precios mucho más bajos que los del mercado. Existía también la práctica de entregar materias primas como algodón para obligar a las muje-

31 Lovell, W. George y Lutz, Christopher: Demography and Empire. A Guide to the Population History of Spanish Central America, 1500-1821, Boulder, Colorado, 1995, pág. 7.

32 Lutz, Christopher: Historia Sociodemográfica de Santiago de Guatemala, 1541-1773, Antigua Guatemala, 1982, pág. 11.

33 Wortman: Gobierno y sociedad..., capítulo 4. 
res de las aldeas a su hilado y en ocasiones a su tejido. Los comerciantes también se aseguraban una salida para sus mercancías de importación o de producción local como azadones, al obligar a los indígenas a comprarlas a precios inflados. A través de estas prácticas se ponía en marcha un gran movimiento de mercancías entre las distintas regiones del Reino de Guatemala: las magistraturas de Nicaragua producían algodón, que era transportado al valle de Guatemala y a la región de Chiapas para la producción de hilo y textiles. Las manufacturas chiapanecas, junto con el cacao y la cochinilla conseguidos en las provincias de la costa del Pacífico, se enviaban a Oaxaca. México era también el destino de algunos de los textiles producidos en el altiplano guatemalteco, pero el grueso se dirigía a los campos mineros de Tegucigalpa y a las zonas productoras de añil de San Salvador. ${ }^{34}$ Parte de la producción de hierro de la provincia de San Salvador se enviaba a las zonas urbanas o se transformaba en azadones que se introducían entre las poblaciones indígenas del valle de Guatemala, el altiplano o Chiapas. Estas prácticas compulsivas eran realizadas por los alcaldes mayores y los comerciantes, quienes formaban sociedades que durante los últimos años del siglo XVII y los primeros del XVIII tuvieron un tremendo desarrollo. Este hecho determina que el repartimiento no pueda ser ya considerado como una simple acción corrupta sino como la forma más importante de movimiento de mercancías en el interior del Reino de Guatemala. Según Robert Patch, el repartimiento no sólo era "la manera de mantener una burocracia a bajo costo, y considerable beneficio para la Corona", sino que "era un rasgo esencial del intercambio comercial, ya que las fuerzas del mercado por sí solas no habrían tenido como resultado la transferencia de beneficios desde los campesinos en la escala requerida por la clase mercante". ${ }^{35}$

La importancia del repartimiento era de tal magnitud que ningún comerciante podía realizar sus negocios sin establecer una relación comercial con un alcalde mayor, o sin ocupar él mismo una de las magistraturas provinciales. Algunos comerciantes vieron cómo su capital crecía al mismo ritmo que la lista de magistraturas ocupadas. Uno de los casos más espectaculares de aprovechamiento personal de las magistraturas provinciales nos lo ofrece Manuel de Lacunza, un vasco-navarro emigrado en la primera década del siglo XVIII que consiguió una cuantiosa fortuna a través del

34 Patch, Robert W.: "Imperial politics and local economy in Colonial Central America, 16701770”, Past and Present, 143, Mayo 1994, pág. 102.

35 Ibídem, págs. 78 y 80. 
repartimiento de mercancías y las actividades asociadas. Por medio de sus conexiones familiares ${ }^{36}$ consiguió introducirse en los recovecos de la burocracia colonial, escalando puestos al mismo tiempo que expandía sus negocios. Lacunza empezó siendo teniente de alcalde mayor en San Antonio Suchitepéquez en los años 1711-1712. Más tarde consiguió el corregimiento de Quezaltenango y la propia alcaldía mayor de San Antonio Suchitepéquez, aunque en forma de futuras. De hecho tardaría casi ocho años en ocupar de forma efectiva este cargo. Desde su puesto en Quezaltenango, que empezó a servir en 1734, organizó una extensa red de negocios que iba desde Oaxaca a México capital, Perú e incluso a Cádiz. Al pasar a ocupar la alcaldía mayor de Suchitepéquez en 1739, se aseguró el control de Quezaltenango, pues logró mantener esta magistratura bajo el mando de uno de sus apoderados. De esta manera, Lacunza ocupó a la vez los dos lugares de la asociación, el de comerciante y el de alcalde mayor. Desde Suchitepéquez, Lacunza enviaba a Santiago de Guatemala hilo de algodón, cacao y dinero procedente de la población indígena. Su aliado en Santiago, el comerciante Francisco de Granda, adelantaba el pago del tributo en los tercios de San Juan y Navidad y se encargaba después de la conversión en dinero de los productos remitidos por Lacunza.

La asociación Lacunza-Granda se parecía mucho a la establecida por Miguel Eustaquio de Uría con Gabriel de la Peña, a la sazón alcalde mayor de Huehuetenango. Uría se constituyó como fiador del magistrado el 6 de julio de 1727. El comerciante se responsabilizaba del pago del tributo a las Cajas Reales mientras que de la Peña se comprometía a repartir azadones, provenientes de los ingenios de hierro de Uría, fardos de hilo (para confeccionar tejidos) y otros productos entre los indígenas. Desde Ciudad Real de Chiapa el funcionario remitía después la producción (sobre todo textiles) a Oaxaca, Campeche, Puebla e incluso a Veracruz, donde podía ser convertida en dinero. Tras la muerte de Gabriel de la Peña, Uría, como su albacea, tuvo que encargarse del arreglo de las cuentas y fue nombrado justicia mayor de Chiapa interino por un año. ${ }^{37}$

No fueron sólo comerciales las actividades desarrolladas por los hombres de negocios guatemaltecos en esta primera mitad del siglo XVIII. En un constante afán por la diversificación, en aras de una mayor seguridad,

36 Mira, Guillermo y Santos Pérez, José Manuel: "Estrategias de integración y ascenso social de emigrantes españoles a América en el siglo XVIII", en Alcántara, Manuel (ed.): América Latina. Realidades y perspectivas, Salamanca, 1997.

37 AGCA. A1-20, 866, exp. 9359. Protocolos de Antonio González. 
invirtieron en tierras, sobre todo las dedicadas al alimento del ganado, y en algunos casos, como el de Uría, incluso dedicaron recursos a la producción minera. Existió una producción argentífera de cierta importancia en las cercanías de Tegucigalpa, pero las características de estas explotaciones mineras, con rudimentarios medios técnicos y muy baja capitalización, determinó que muy pocas veces los comerciantes se Guatemala invirtieran directamente en ellas. La relación tenía un carácter indirecto, a través de habilitaciones (créditos similares a los otorgados a los productores de añil), o bien por medio del alcalde mayor de turno que solía tener un fácil acceso a los metales preciosos, muy importantes para los intercambios comerciales dentro y fuera de la región. El hecho de que los comerciantes fueran quienes garantizaban los insumos de la minería (escasos, dado el bajo nivel tecnológico de las explotaciones), y el transporte de la producción hasta Guatemala, determinaba que se llevaran la parte del león en detrimento de los productores directos, quienes permanecían en una situación de dependencia. Ya hemos visto cómo Juan José González Batres tenía a Tegucigalpa como el principal centro de sus habilitaciones. También Francisco Marcelino Falla tenía una especial relación con esta zona minera, reflejada claramente en los protocolos notariales. ${ }^{38}$ Uno de los casos más interesantes nos lo proporciona Diego Arroyave y Beteta, hijo del comerciante Ventura Arroyave y Beteta, que ocupó desde 1743 la alcaldía mayor de Tegucigalpa. Arroyave, desde su privilegiada plataforma, se responsabilizó durante su ejercicio de la adquisición y conducción de la plata desde las minas hasta los más significativos comerciantes de la capital, entre los que se encontraba su propio padre, Ventura de Arroyave y Beteta. ${ }^{39}$ Entre el 6 de febrero y el 30 de julio de 1745 Ventura recibió de su hijo la cantidad de 1.093 marcos de plata en barras. Según Linda Newson, la plata se podía cambiar en Guatemala con una ganancia de 5 a 10 reales por marco, dependiendo de su calidad. ${ }^{40}$

38 AGCA. A1-20, leg. 1281, fol. 16, fol. 19, fol. 4v., etc. Protocolos de Mateo Ruiz Hurtado, 29 de enero de 1726, diversas obligaciones de pago de vecinos de Tegucigalpa a favor de Francisco Marcelino Falla.

39 AGI. Guatemala, 234. "Testimonio de los autos fechos en este superior gobierno sobre la conduzion de platas de Thegusigalpa con las demas probidencias a este fin conduzentes", 1745. Según T. S. Floyd: "the decadence of supervision of the mines is further illuminated in the fact that the leading rescatadores of the mining region were the alcalde mayor of Tegucigalpa and his tenientes." "Bourbon Palliatives and the Central American Mining Industry", The Americas, vol. 18, n. ${ }^{\circ}$, octubre 1961, pág. 113.

40 Newson, Linda: "La minería de plata en la Honduras colonial”, en Cáceres, Luis R. (ed.): Lecturas de Historia de Centroamérica, San José, 1989, pág. 121. 
Durante la primera mitad del siglo XVIII se produjo también un cierto nivel de inversión en la minería de hierro. En el oriente de la actual República de Guatemala y en el valle de Metapas en San Salvador existía una producción irregular de hierro que abastecía la demanda local ante la escasa cantidad de metal que llegaba desde Cádiz. La ciudad de Santiago de Guatemala, que tenía una intensa actividad constructora tras los periódicos movimientos sísmicos, era el principal mercado del metal. Por otra parte, los azadones y otras herramientas fabricadas en los ingenios de hierro eran uno de los productos más comunes "repartidos" forzosamente por los alcaldes mayores entre la población indígena de sus jurisdicciones. No existen datos fiables del total de hierro producido en el Reino de Guatemala en el siglo XVIII. Sólo disponemos de algunas noticias sobre las cantidades introducidas a través de la aduana de Santiago. Entre 1720 y 1729 pasaron por el control aduanero 1.176 quintales de hierro, según los datos proporcionados por José Antonio Fernández Molina. La financiación de la producción del metal solía venir de los comerciantes de la capital, aunque lo hacían en menor cantidad que con la producción de añil o la de plata. Los comerciantes eran reacios a desviar la siempre limitada cantidad de crédito desde la rentable zona añilera a la inestable y poco fiable producción férrica. ${ }^{41}$

Miguel Eustaquio de Uría fue uno de los más activos participantes en el sector minero en esta primera mitad de siglo. El 20 de febrero de 1732 compró dos ingenios de fabricación de hierro en San Salvador, situados en la localidad de Santa Ana, en el valle de Metapa. En el lote, por el que Uría pagó 16.500 pesos, se incluían 4 esclavos y un terreno de dos caballerías y cuatro cuerdas, además de una veta de hierro de donde se extraía el mineral. La vocación de minero de Miguel Eustaquio duró poco tiempo. En 1735 alquiló los terrenos a un tal Manuel Ximénez de Cisneros, quien se comprometía a pagar 2.000 quintales de hierro en 10 años y a no enajenar ninguno de los bienes de los ingenios. El arrendatario no pudo cumplir las condiciones, bien a causa de una mala gestión o por lo cuantioso de la cifra que tenía que pagar cada año. Las minas fueron cedidas entonces a Felipe Ruiz de Contreras, quien realizó un nuevo contrato de arrendamiento con Uría en 1739, en términos más realistas. Se comprometió a entregar una cantidad de hierro casi cuatro veces menor a lo exigido inicialmente. Tras

41 Fernández Molina, José Antonio: “Al estilo de Vizcaya ...” La producción de hierro en el Reino de Guatemala, Guatemala, 1989, pág. 12. 
la muerte de Uría, los albaceas hicieron un nuevo contrato de arrendamiento y finalmente, en 1752, las minas fueron vendidas a José Mendez por 6.500 pesos, casi tres veces menos de lo pagado por Uría 20 años antes. ${ }^{42}$ Esta pérdida de valor de la explotación refleja sin duda las nuevas condiciones que se dieron hacia mediados de siglo, momento en que la mayor afluencia de barcos de registro a las costas hondureñas aseguró el aprovisionamiento de hierro procedente de España, con la consiguiente caída de precios.

Las inversiones en tierras dedicadas a la agricultura para la exportación, el consumo interno o la ganadería figuraban también entre los más importantes rubros de los libros de contabilidad de los comerciantes guatemaltecos de esta primera mitad de siglo. Aunque no se observa un significativo acaparamiento de tierras, sí parece advertirse un interés por adquirir un número de terrenos suficiente con el que respaldar inversiones futuras. En esta primera mitad de siglo, la mayor parte de las tierras compradas eran potreros situados en el Valle de Guatemala, es decir, tierras dedicadas al engorde del ganado. ${ }^{43}$ La ganadería ocupaba un lugar muy importante en la economía regional, tanto la de vacuno, destinada al abastecimiento de los núcleos urbanos, como la caballar y mular, destinada al transporte de mercancías por tierra, tan importante en este período. Prueba de la importancia de la ganadería en la Centroamérica de principios del XVIII es que algunas operaciones de venta de mercancías se cierran con el compromiso del comprador de pagar en reses, normalmente en el plazo de un año. ${ }^{44}$

Hemos visto, por lo tanto, después de examinar las actividades de algunos de los más importantes "hombres de negocios" del Reino de Guatemala, que la economía colonial de la primera mitad del siglo XVIII no

42 AGCA. A1-20, leg. 863, exp. 9356. Protocolos de Antonio González, "Poder especial para vender las posesiones que aquí se expresan ...”, año 1735. AGCA. A1-20, leg. 1139, exp. 9632, fol. 49. Protocolos de Hipólito Ordóñez, "Dejación de dos ingenios de fierro y arrendamiento de ellos entre don Miguel de Uría y don Phelipe Ruiz de Contreras", año 1739. AGCA. A1-20, leg. 1141, exp. 9634, fol. 87. Protocolos de Hipólito Ordóñez, "Arrendamiento de dos ingenios de fierro". AGCA. A1-20, leg. 879, exp. 9372, fol. 441v. Protocolos de Antonio González, "Escritura de venta de dos ingenios de hierro, Catharina González Batres, viuda de Miguel de Uría a favor de don José Mendez”, año 1752.

43 AGCA. A1-15, leg. 2300, exp. 16892. "Testimonio de los autos hechos sobre el remate de las haziendas de campo, ingenio y potrero que quedaron por vienes del capitán don Joseph del Castillo y Aguilar que se celebró en su merced el capitán don Miguel Eustachio de Uría, alcalde hordinario de primer voto en esta ciudad por su magestad", 1722.

44 AGCA. A1-20, leg. 1272, fol. 17v. Protocolos de Mateo Ruiz Hurtado, 27 de enero de 1717, Juan Bautista Escoto, vecino de Tegucigalpa, a favor de don Francisco Marcelino Falla, obligación de pago de 1.538 pesos 2 rs por la compra de una memoria de géneros, "a pagar en un año en ganado al precio corriente que tubiere en Serro Redondo y por defecto de dho. ganado haremos en rs. dha. paga". 
tiene esas características de parálisis que tantas veces han dibujado los historiadores. El comerciante guatemalteco de la época, consciente de las dificultades existentes para la exportación a través de los canales oficiales, buscaba sus oportunidades en otras rutas. Compraba añil en El Salvador, en cantidades seguramente menores que en los años posteriores, pero de ningún modo despreciables. Transportaba el añil por la ruta mexicana hacia Veracruz, pero dejando también importantes cantidades en Oaxaca que serían reintroducidas en el mercado novohispano, sobre todo en Puebla y la capital. Para ello nombraba agentes en las ciudades mexicanas, que actuarían como delegados comerciales. Conducía asimismo el añil y otras mercancías de la región, como brea y vainilla, hacia Perú y hacia los puertos de Honduras donde había establecido contactos con los británicos que merodeaban en esas costas. Para realizar estas actividades invertía capital en la compra de uno o dos barcos, que le permitirían también llevar sus mercancías hacia La Habana, un puerto que, junto con Veracruz, era el auténtico almacén de los productos de exportación centroamericanos. Nuestro comerciante se cuidaba de crear una sociedad con un alcalde mayor, o actuar él mismo como tal, para asegurarse el aprovisionamiento a muy bajo costo de productos de exportación como cacao, o de mercancías imprescindibles para el comercio con San Salvador, como "ropa de la tierra". Frecuentemente invertía en tierras, no en grandes extensiones, sino en las suficientes para apacentar el ganado que compraba cada año, un ganado que le serviría para obtener cuantiosos beneficios en el abastecimiento de carne a las ciudades, sobre todo a Santiago de Guatemala, y en ocasiones para utilizarlo en el intercambio con San Salvador. Eventualmente dedicaba unas tierras a la cría de mulas, que tenían gran demanda ahora por la importancia del tráfico terrestre de mercancías. El comerciante guatemalteco establecía también contactos en Tegucigalpa, bien a través de un alcalde mayor o por medio de la concesión de créditos, donde podía obtener el metálico necesario para engrasar las operaciones comerciales. Todas estas operaciones se podían dar por separado, aunque en algunas ocasiones, como en el ejemplo de Uría, se juntaban para darnos como resultado un espectacular caso de diversificación de actividades y de éxito en los negocios en un momento de dificultades en el transporte, y en una región de acusada marginalidad dentro del entramado colonial hispano en América.

Debemos pensar en términos distintos sobre la economía centroamericana de este período. Parece que nos encontramos más bien ante una sucesión de crisis cíclicas, en la línea de Wortman, que ante una gran crisis 
general motivada por las supuestas dificultades en la exportación. No cabe duda de que el declive fue largo y profundo en las relaciones directas con Cádiz a través de los navíos de registro, pero ello no determinó una parálisis de las relaciones económicas. Nuestros comerciantes encontraron y aprovecharon con beneficio las numerosas grietas que la economía oficial dejaba en el sistema colonial. 